\section{Ana Conçalves Magalhães}

Museu de Arte Contemporấnea da

Universidade de São Paulo (MAC/USP)

\title{
A disputa pela arte abstrata no Brasil: revisitando o acervo inicial do Museu de Arte Moderna de São Paulo, 1946-1952
}

The quest for abstract art in Brazil: revisiting the primary collection of the São Paulo's Museum of Modern

Art, 1946-1952

\section{Resumo}

Pretende-se analisar aqui as contradições que emergem das duas campanhas de aquisição de obras (respectivamente em 19461947 e 1952-1954) que o primeiro presidente e patrono do Museu de Arte Moderna de São Paulo (MAM), Francisco Matarazzo Sobrinho, realizou na Itália. Nossa intenção é propor uma releitura do debate sobre a arte abstrata no contexto brasileiro em torno da criação do MAM e da Bienal de São Paulo, bem como reavaliar as ligações do ambiente artístico paulista com o meio artístico italiano, na busca de novos caminhos em direção à abstração. Esse estudo tem por objetivo revisar a narrativa de arte moderna no Brasil, tal como foi consolidada pela historiografia brasileira. Palaviras-chave: Figurativismo; Abstrcionismo; Museu de Arte Moderna de São Paulo; Acervo; Bienal de São Paulo; Arte moderna italiana.

\begin{abstract}
This paper intends to analyze the contradictions emerging from the two groups of artworks that the first chairman and patron of the São Paulo Museum of Modern Art (MAM), Francisco Matarazzo Sobrinho, bought in Italy (respectively in 1946-1947 and 1952-1954). The proposal is to offer a new reading of the abstract art debate in the Brazilian context of the creation of MAM and the São Paulo Biennial, as well as to look into the long-term liaisons that the São Paulo artistic milieu had established with its Italian counterparts, when' searching for new paths towards abstraction. Such study aims to review the narrative of modern art in Brazil, as consolidated by Brazilian historiography.
\end{abstract}

Keywords: Figuration; Abstraction; São Paulo Museum of Modern Art; São Paulo Biennial; Italian modern art.

Uma versão preliminar deste texto foi apresentada em forma de comunicação na sessão "Reconstructing Complexity: Art in Brazil at the Mid-Century and After World War II" [Reconstruindo a complexidade: arte no Brasil em meados do século e depois da II Guerra Mundial], coordenada por Adèle Nelson (Temple University), no XIII Congresso da Brazilian Studies Association, na Brown University, em Providence, Rhode Island, em março de 2016 (MACALHÃES, 2016 b). 

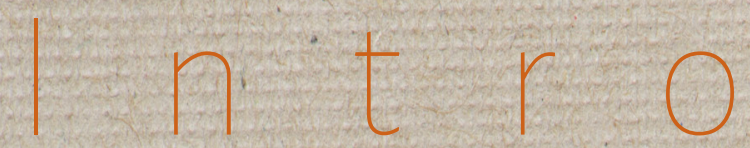

$C$

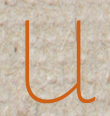

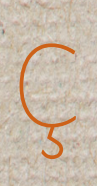
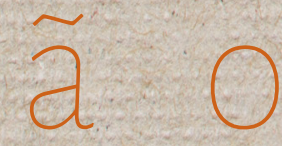

presente artigo apresenta pesquisa em andamento em torno do acervo de arte moderna do Museu de Arte Contemporânea da Universidade de São Paulo (MAC/USP), recebido do Museu de Arte Moderna de São Paulo (MAM) em 1963․ Apresentar essas reflexões no contexto do dossiê Escrita da História pareceu oportuno, uma vez que sua chamada se abriu para pesquisadores de diferentes áreas de conhecimento que lançam mão da prática historiográfica, mas que privilegiam o trabalho de outros campos de pesquisa, com outros objetos, em especial imagens. Nesse sentido, um acervo de museu é material instigante de trabalho para a escrita da história, para além da narrativa sobre a produção dos objetos ali existentes. No caso do acervo de arte moderna do MAC/USP, e a partir da perspectiva que nos inte-

10 Museu de Arte Contemporânea (MAC/USP) foi fundado na Universidade de São Paulo em abril de 1963, para receber o acervo do Museu de Arte Moderna (MAM) de São Paulo. Entre 1962 e 1963, fez-se a separação entre o evento Bienal de São Paulo e o MAM, e teve início a discussão e processo de transferência do MAM e seu acervo para a USP. Para uma análise atualizada desse processo, ver Magalhães (2016, p. 23-57). ressa trabalhar, a evidência das obras tem nos conduzido a reavaliar e a rever a narrativa propagada sobre a história da arte moderna no Brasil e sobre a constituição do primeiro museu de arte moderna da América do Sul.

Costaríamos, portanto, de proporuma breve análise crítica da maneira através da qual a historiografia brasileira vem narrando a formação do Museu de Arte Moderna de São Paulo (MAM), e da Bienal de São Paulo, como plataformas de debate sobre arte abstrata no Brasil2. Nesta narrativa, há pelo menos três elementos que a definem e parecem ser contraditórios aos programas de aquisição de obras de arte reunidas naqueles anos de formação do acervo do museu. O primeiro elemento é a ideia de que haveria uma continuidade entre o discurso artístico que embasou a criação do MAM e aquele que deu origem a uma exposição sazonal como a Bienal em São Paulo. O segundo concerne à noção de

2 Referimo-nos aqui em particular aos escritos de Maria Cecília França Lourenço (1999), Annateresa Fabris (2008), e Luís Camillo Osório e Annateresa Fabris (2008). 
arte concreta que circulava no Brasil naquele período. E o terceiro elemento envolve uma hegemonia de modelos norte-americanos que influenciaram a formação dessas instituições.

Propomo-nos a questionar esses aspectos à luz das obras de arte adquiridas para o antigo MAM $^{3}$ entre 1946 (antes de sua efetiva fundação) e 1952 (um ano depois da primeira edição da Bienal de São Paulo), para repensar quais debates artísticos possam ter fomentado tais aquisições, bem como sua relevância para o cenário artístico internacional. Assim, trataremos precisamente desses programas de aquisição, confrontando-os com exposições que ajudaram a constituir uma narrativa sobre arte moderna abstrata para a historiografia brasileira. Comecemos por uma breve história da formação dessas instituições paulistas, para depois abordar os dois programas de aquisição em questão - levados a cabo pelo então presidente do

3 Adotamos aqui a expressão "antigo MAM" para nos referir à primeira fase de funcionamento do museu (1948-1962), considerando-se que a transferência de seu acervo para a USP, entre 1962 e 1963, teve por objetivo inicial a transferência da administração do museu para a Universidade - o que nunca ocorreu. A partir de 1969 entra em operação um novo MAM, com nova pessoa jurídica e novo acervo, ainda que até hoje a historiografia assinale a continuação do projeto inicial. (Cf. Osório e Fabris, 2008).
MAM e seu patrono, Francisco Matarazzo Sobrinho ${ }^{-}-\mathrm{e}$, finalmente, voltar aos três elementos que fundamentaram nossa narrativa de arte moderna diante de novas evidências, trazidas pelo estudo das aquisições aqui analisadas.

A ideia de criar um museu de arte moderna em São Paulo já estava em discussão desde o fim da década de 1930. Nos escritos do crítico de arte Sérgio Milliet (1944, p. 255) - que viria a ser o primeiro interlocutor com o Museu de Arte Moderna de Nova York (MoMA) pára a criação de museus de arte moderna no Brasil-o Museu não deveria ter sido apoiado pela iniciativa privada, e sim pela Prefeitura de São Paulo,

4 Francisco Matarazzo Sobrinho, conhecido como Ciccillo Matarazzo (1898-1977), pertencia a uma abastada família de imigrantés italianos (da região de Salerno, sul da Itália), em São Paulo, e esteve à frente da Metalúrgica Matarazzo, empresa por ele criada, ao separar seus negócios de seu tio, Conde Francesco Matarazzo (que imigrara para o Brasil em 1881, e já nos anos 1920 tinha um dos maiores impérios industriais da América do Sul). Ciccillo estabeleceu sua identidade como um mecenas das artes, incentivando particularmente a arte moderna, a partir da década de 1940. Além de ser fundador e presidente do Museu de Arte Moderna de São Paulo, foi responsável pela criação de outros equipamentos culturais importantes da cidade, tais como a Bienal de São Paulo, a Cinemateca Brasileira, o Teatro Brasileiro de Comédia e a Companhia Cinematográfica Vera Cruz - a primeira do país. Sua biografia, de autoria de Fernando Azevedo de Almeida (1976), permanece sendo a única fonte sobre a vida de Matarazzo. 
assim como deveria ter se espelhado em projetos de mesma natureza na Europa 5 .

Quando finalmente tomou corpo, o projeto de um museu de arte modernà para São Paulo foi discutido por patronos privados, críticos de arte e artistas que haviam começado a se reunir a partir de $1945^{6}$. Nas reuniões da comissão oficial de criação do MAM, Milliet reportava a presença do diplomata norte-americano Carleton Sprague Smith, seu colega na Escola Superior de Sociologia e Política, e membro do Conselho de Administração do Museu de Arte Moderna de Nova York (MoMA) naquele momento. A partir de 1946 , foi cada vez mais imponente a presença do empresário ítalo-brasileiro Francisco Matarazzo

5 Em 1937, Milliet viaja a Paris como representante do Departamento de Cultura da Prefeitura de.São Paulo, para visitar a Exposição Universal, naquele momento instalada no novo complexo erguido no Trocadéro, na capital francesa. Embora em nenhum momento, em seus depoimentos e ensaios, ele fale especificamente de nenhum projeto de museu de arte moderna, Milliet certamente foi testemunha da experiência do Musée des Écoles Étrangères Contemporaines, extensão do Musée do Luxembourg, então instalado no paviIhão do Jeu de Paume, nas Tulherias, que tinha inaugurado, um ano antes, a Calérie de l'École Contemporaine de Peinture Italienne, cujas obras haviam sido doadas à nação francesa através do Comitê para-diplomático France-Italie. São justamente as atividades e o formato do Musée dés Écoles Étrangères Contemporaines de Peinture que dão origem ao Musée National d'Art Moderne, no pós-guerra.

6 Sobre a criação do antigo MAM, ver Nascimento (2003), Barros (2002) e Fabris (2008).
Sobrinho nessas negociações, que por fim acabou por se tornar o principal contato com as instituições estrangeiras e seus representantes (Imagem 1).

Imagem 1- Francisco Matarazzo Sobrinho e Nelson Rockefeller (1948).

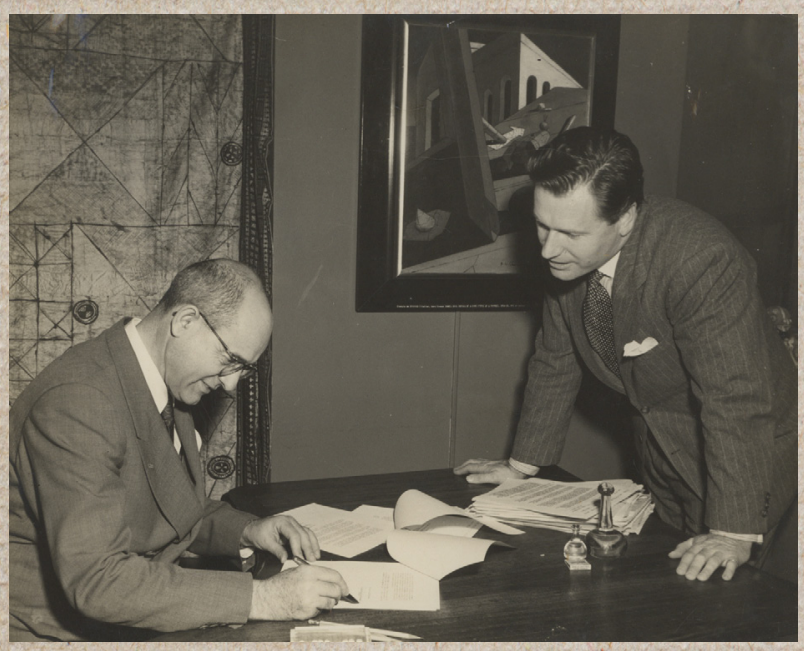

Fonte: Fundo Francisco Matarazzo Sobrinho, Arquivo Histórico Wanda Svevo, Fundação Bienal de São Paulo. Fotografia de Leo Trachtenberg. OTrayton Studios.

Neste mesmo ano, Matarazzo tomou para si a tarefa de adquirir obras de arte para o acervo do futuro MAM (MACALHÃES, 2016). As aquisições se intensificam dois meses antes que Nelson, Rockefeller ${ }^{7}$ chegasse com quatorzé obras a serem doadas ao Brasil, um incentivo para a criação de museus de arte moderna, tanto em São Paulo quanto no Rio de Janeiro: Se Rockefeller lançou mão dos curado-

\footnotetext{
7 O herdeiro de uma das mais ricas famílias da indústria petrolífera norte-americana era, naquele momento, Secretário do Office of Interamerican Affairs e membro do Conselho de Administração do MoMA. Sobre as relações entre Rockefeller e o Brasil, ver Tota (2014).

8 Sobre a história das doações de Nelson Rockefeller nesse contexto, ver Toledo (2015).
} 
res do MoMA para fazer a seleção de obras que constituíam um panorama da arte moderna-ao menos do ponto de vista de como a cena nova-iorquina a definia naquele momento - Matarazzo voltou-se para outros territórios e agentes. Suas primeiras aquisições para o MAM, feitas entre Milão, Roma e Paris, tiveram como mediadores dois personagens fundamentais oriundos do meio artístico italiano, o pintor abstrato italiano Alberto Magnelli e a crítica de arte e jornalista Margherita Sarfatti, que desde 1939 vivia exilada na América do Sul?

As escolhas de Magnelli em Paris seriam suplantadas pelas aquisições intermediadas por Sarfatti na Itália. Isso certamente causaria grande impacto na história da arte moderna, sobre o qual essas obras podem nos contar. Mesmo que a seleção de Magnelli desse ênfase às recentes experimentações da pintura abstrata em Paris - ao selecionar um Wassily Kandinsky de 1942 (Composição clara, óleo sobre tela, MAC/USP) - Sarfatti e seus colabora-

9 Sobre Alberto Magnelli (1888-1971), ver Abadie (1993). E sobre Margherita Sarfatti (1880-1961), além do livro de minha autoria (que foca sobre seus perçursos na América do Sul), destacam-se as biografias de Phillip Cannistraro e Brian Súllivan (1993), e de Françoise Liffran (2009). dores rejeitaram a abstração e enfatizaram experiências com a pintura figurativa e certa noção de classicismo, na arte moderna, típica de sua defesa do chamado grupo do Novecento Italiano, criado nos anos 1920 e cooptado como a principal tendência da propaganda artística do regime fascista nos anos $1930^{10}$. Ainda que o conjunto de setenta e uma pinturas compradas por Matarazzo na Itália, ao longo de uma campanha que durou dez meses, não possa ser interpretado somente dentro da chave do Novecento Italiano, essa noção prevaleceu, em grande medida, devido ao seu uso num contexto de reformulação das instituições culturais italianas no segundo pós- guerra e sua necessidade de renovar laços com a América do Sul e os Estados Unidos.

Portanto, se uma obra como A adivinha, de Achille Funi (Imagem 2), parece ter dado o tom geral de leitura da coleção comprada entre 1946 e $1947^{11}$, a presença de obras de artistas como Renato Birolli, Afro Basaldella (Imagem 5) e Renato Guttuso, entre outros, é uma

10 Sobre o Novecento Italiano, ver Bossaglia (1995).

11 Ainda de Mario Sironi, ver Os pescadores (Imagem 3); e de Massimo Campigli, ver Mulheres a passeio (Imagem 4). 
evidência das preocupações dos intermediários de Matarazzo de apresentár renovações artísticas, em oposição aos estilemas promovidos até o fim do'regime fascista. Além disso, tais artistas não só haviam se engajado em atividades antifascistas durante a II Guerra Mundial, mas também foram pioneiros da reconexão do meio artístico italiano com Paris, e protagonizaram um debate feroz, que emergiu no fim da guerra, sobre qual deveria ser a nova linguagem da pintura a partir de então. Tal debate ganhou contornos ideológicos quando esses artistas se alistaram no Partido Comunista Italiano, questionando valores expressos por uma pintura puramente abstrata - entendida como individual e simplesmente decorativa, representativa dos valores de uma sociedade liberal. Nesse momento, os partidos comunistas de toda a Europa fizeram a defesa de uma pintura figurativa, considerada então como a única capaz de expressar valores humanos e preservar a ideia de coletividade na prática artística ${ }^{12}$. Aqui no Brasil, a pintura figurativa também era entendida como uma linguagem ligada a certa

12. Para um aprofundamento sobre, essa questão, ver Amaral (2003, p. 239). noção de realismo que, por sua vez, exprimia valores humanos apreciados por esses grupos ${ }^{13}$. Esse debate atingiu seu, clímax nas duas primeiras edições da Bienal de Veneza do imediato pós-guerra, ou seja, em 1948 e 1950, como tem sido apontado por estudos recentes ${ }^{14}$.

Imagem 2 - A adivinha (1924), de Achille Funi. [óleo sobre madeira, $45,7 \times 46,8 \mathrm{~cm}]$

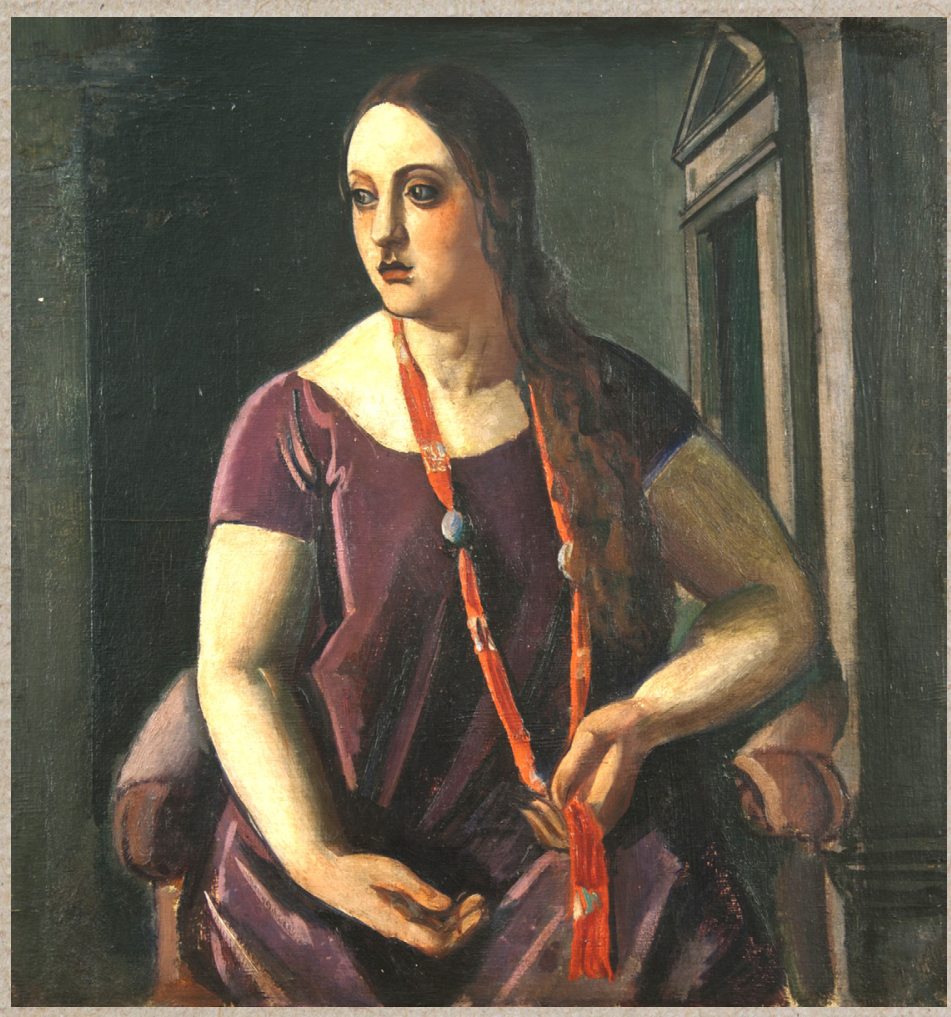

Fonte: Coleção Francisco Matarazzo Sobrinho (MAC/USP). Fotografia de Márcia Rizzutto e Elizabeth Kadija (2012).c Museu de Arte Contemporânea, Universidade de São Paulo.
13 Tratam-se de artistas ligados, inicialmente, ao chamado Cruppo Corrente di Vita Giovanile, e depois ao Fronte Nuovo delle Arti (CARAMEL, 1994).

14 Nancy Jachec (2007) dedica os primeiros capítulos de seu livro a tratar justamente da política externa norte-americana e sua intervenção direta no contexto político italiano dado o crescimento do Partido Comunista naquele país, bem como o embate com a intelectualidade e o meio artístico italiano neste contexto. 
Imagem 3 - Os pescadores (1924), de Mario Sironi. [óleo/tela, $708,8 \times 89,4 \mathrm{~cm}$ ]

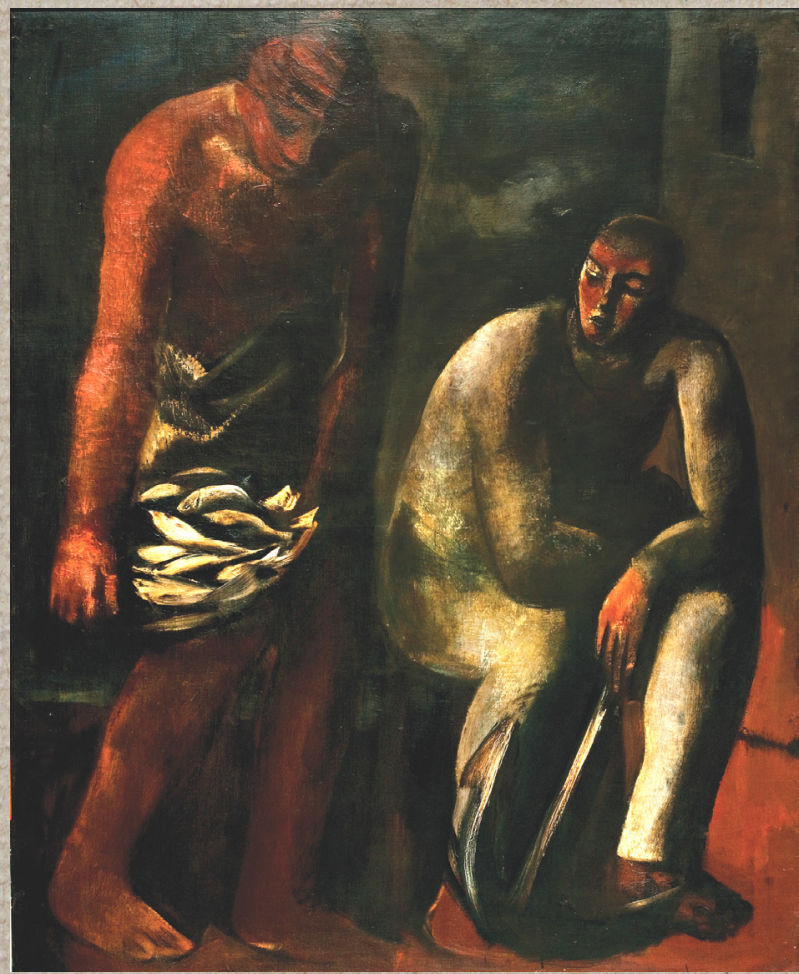

Fonte: Coleção Francisco Matarazzo Sobrinho (MAC/USP). Fotografia de Rômulo Fialdini (2017). (o Mario Sironi / AUTVIS, Brasil, 2016.

Imagem 5-Retrato de Adriana (7946), de Afro Basaldella. [óleo/tela, $653,7 \times 50,6 \mathrm{~cm}$ ]

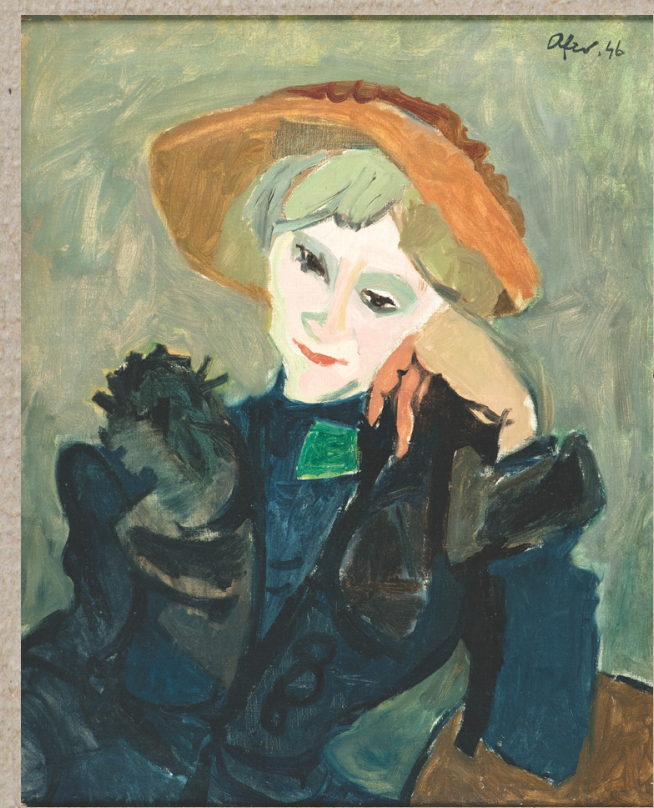

Fonte: Coleção Francisco Matarazzo Sobrinho (MAC/USP). Fotografia de Rômulo Fialdini (2017). () Afro Basaldella / AUTVIS, Brasil, 2016
Imagem 4-Mulheres a passeio (1929), de Massimo Campigli. [óleo/tela, $80,9 \times 64,6 \mathrm{~cm}$ ]

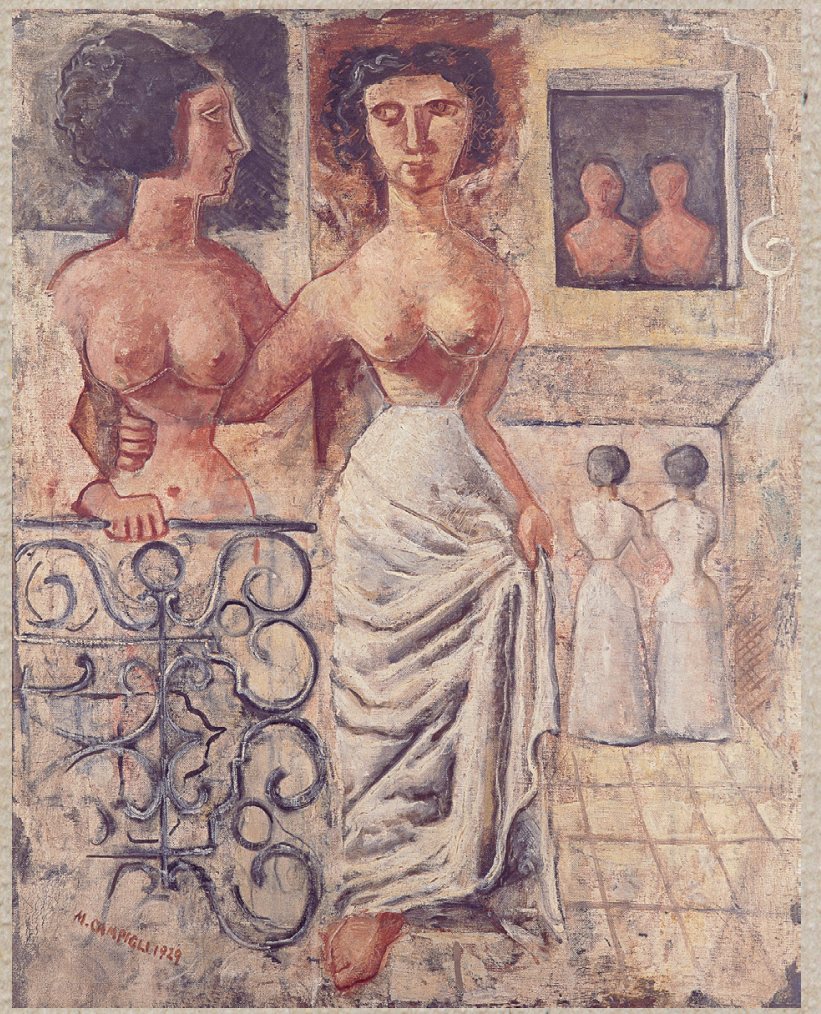

Fonte: Cóleção Francisco Matarazzo Sobrinho (MAC/USP). Fotografia de Rômulo Fialdini (2011). (c) Massimo Campigli | AUTVIS, Brasil, 2016

O MAM foi inaugurado em março de 1949 - justamente no intervalo entre essa primeira aquisição e a criação da Bienal de São Paulo - com a exposição Do Figurativismo do Abstracionismo (Imagem 6) ${ }^{15}$, tendo o crítico de arte belga Léon Dégand como seu primeiro organizador e diretor artístico. Essa mostra itinerou para o Rio de Janeiro, onde também realizou-se uma conferência ${ }^{16}$, que contou com a presença do próprio Dégand e de críticos brasileiros

15 Cf. Dégand (1949a).

16 Cf. Dégand (1949b). Sobre a conferência e a itinerância da mostra Do figurativismo ao abstracionismo no Rio de Janeiro, ver Magalhães (2009). 
importantes, e se deu no formato de um painel de debates entre defensores da pintura abstrata - posição assumida por Dégand-eaqueles que defendiam uma pintura de caráter realista/figurativo. O crítico Mário Pedrosa contribuiu com um ensaio no qual tentou, de algum modo, conciliar essas tendências opostas da pintura moderna, atuando assim como personagem-chave na defesa dos argumentos de Dégand ${ }^{17}$.

O maior opositor de Dégand foi o pintor Emiliano di Cavalcanti ${ }^{18}$, que conde-

Imagem 6 - Vista parcial da mostra Do figurativismo ao abstracionismo, na sede da Metalúrgica Matarazzo (1949).

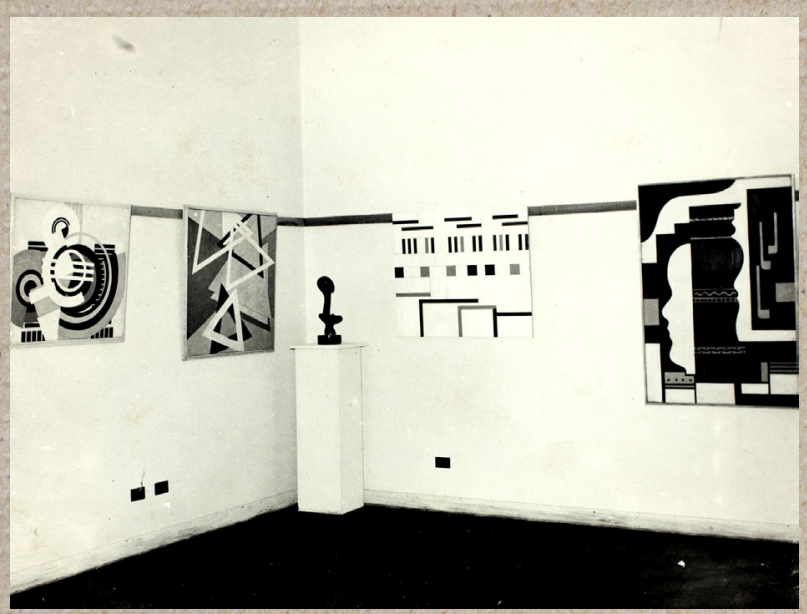

Fonte: Fundo Francisco Matarazzo Sobrinho, Arquivo Histórico Wanda Svevo, Fundação Bienal de São Paulo. (c) Jornal das Artes (1949).

17 Cf. Mário Pedrosa em "As duas alas do modernismo" (apud DÉCAND, 1949b).

18 Cf. Emiliano di Cavalcanti, em "Realismo e abstracionismo" (apud DÉCAND, 1949b). A conferência de Di Cavalcanti basicamente reproduzia seus argumentos de artigo publicado na revista Fundamentos no ano anterior (1948), já em contra-ataque às três conferências proferidas por Dégand em sua chegada como novo diretor artístico do antigo MAM. nou o que acreditava serem aspectos puramente "burgueses" e "decorativos" da pintura abstrata enquanto, a seu ver, a pintura realista seria aquela capaz de exprimir os reais valores "humanistas" da sociedade. Suas obras evidentemente não estiveram presentes na exposição. No lugar dele, apenas três artistas ligados ao ambiente artístico brasileiro foram convidados a participar: Waldemar Cordeiro, Samson Flexor e Cícero Dias, naquele momento apresentados como representantes da pintura abstrata no Brasil ${ }^{19}$. Cordeiro e Flexor eram imigran-

Imagem 7 -Samson Flexore Léon Dégand conversam diante de uma pintura do primeiro na exposição Do figurativismo ao abstracionismo (1949).

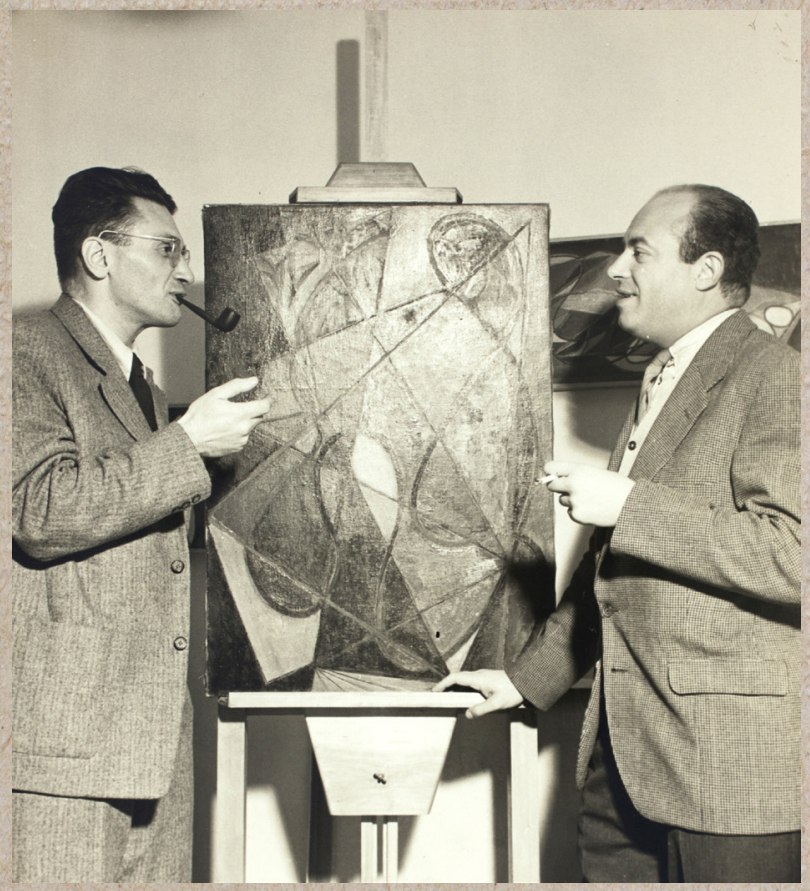

Fonte: Instituto Moreira Salles (c). Fotografia de Henri Ballot.

$19 \mathrm{Na}$ Imagem 7, vemos o artista Samson Flexor conversando com Léon Dégand diante de uma de suas obras expostas na mostra. 
tes recém-chegados ao Brasil, de Roma e Paris respectivamente; e Cícero Dias havia se estabelecido em Paris para levar sua carreira de artista adiante, e iniciava suas experiências com a pintura abstrata.

A parte francesa da mostra acabou sendo a maior em número e a mais importante, uma vez que as negociações com a parte norte-americana da exposição fracassaram. A seleção de obras feitas por John Sweeney, Alfred Barr, com a colaboração do artista Marcel Duchamp, deveria ter complementado as obras vindas da França, com escolha do galerista René Drouin, que, no fim, dominou o panorama da arte abstrata proposta pela exposição ${ }^{20}$.

No que concerne à participação francesa, a historiografia brasileira tem sido unânime em apontar para uma escoIha de artistas ligados às experiências de abstração geométrica dos grupos Cercle et Carré e Abstraction Création (LOU-

20 Acerca do assunto, ver a correspondência entre Francisco Matarazzzo Sobrinho e os organizadores da parte norte-americana. (Fundo Francisco Matarazzo Sobrinho, Arquivo Histórico Wanda Svevo, Fundação Bienal de São Paulo).
RENÇO, 1999, p. 113)21. Esses grupos haviam se desenvolvido ainda na década de 1930 no contexto da emergência, da Arte Concreta, tal como definida por Theo van Doesburg, mas também diante da presença de Wassily Kandinsky na França. De fato, certa reminiscência desse contexto pode ser encontrada no relevo branco de Jean Arp (Imagem 8),

\section{Imagem 8-Formas expressivas (1932), de] ]ean Arp. [madeira pintada (relevo), $84,9 \times 70 \times 3 \mathrm{~cm}]$}

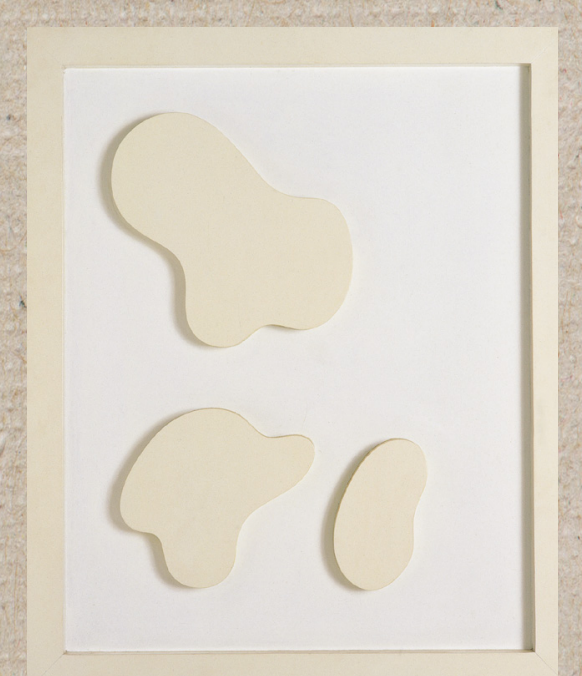

Fonte: Coleção Francisco Matarazzo Sobrinho, MAC/USP. Fotografia de Rômulo Fialdini. () Jean Arp /AUTVIS, Brasil, 2016.

210 grupo Cercle et Carré havia sido criado pelo artista uruguaio Joaquín Torres-García (naquele momento, vivendo em Paris), com o apoio do crítico francês Michel Seuphor, em 1929. Teve apenas um ano de existência, realizando uma exposição e reunindo artistas que naquele momento trabaIhavam com uma linguagem abstrata da arte. Torres-Carcía traria as ideias do Cercle et Carré à América do Sul em meados da década de 1930, com seu retorno ao Uruguai, onde criou um grupo de artistas e uma revista homônima, Círculo y quadrado. A breve experiência do Cercle et Carré se desdobraria na criação do grupo Abstraction-Création em 1931, caracterizado por uma associação de artistas, promotora de exposições de arte abstrata ao longo da década de 1930, em Paris. 
que Matarazzo havia comprado em $\mathrm{Pa}$ ris, entre 1946 e 1947, porintermédio de Alberto Magnelli. Outros artistas dessas correntes também haviam sido adquiridos por Matarazzo no mesmo lote, ainda que essas obras não tivessem sido selecionadas para a exposição. É o caso da pintura de Kandinsky e do relevo de César Domela, que encontravam equi- valentes em outras obras dos mesmos artistas que tinham vindo de Paris para a ocasião (Imagens 9 e 10). Por outro, lado, um mínimo traço do meio artístico nova-iorquino e de seu MoMA sobrevivera com a apresentação de duas obras que Nelson Rockefeller havia doado em 1946: um móbile de Alexander Caldere um guache de Fernand Léger.

Imagem 9-Sem título (1942), de César Domela [madeira, metal e acrílico, $54,2 \times 42,6 \times 4,3 \mathrm{~cm}]$

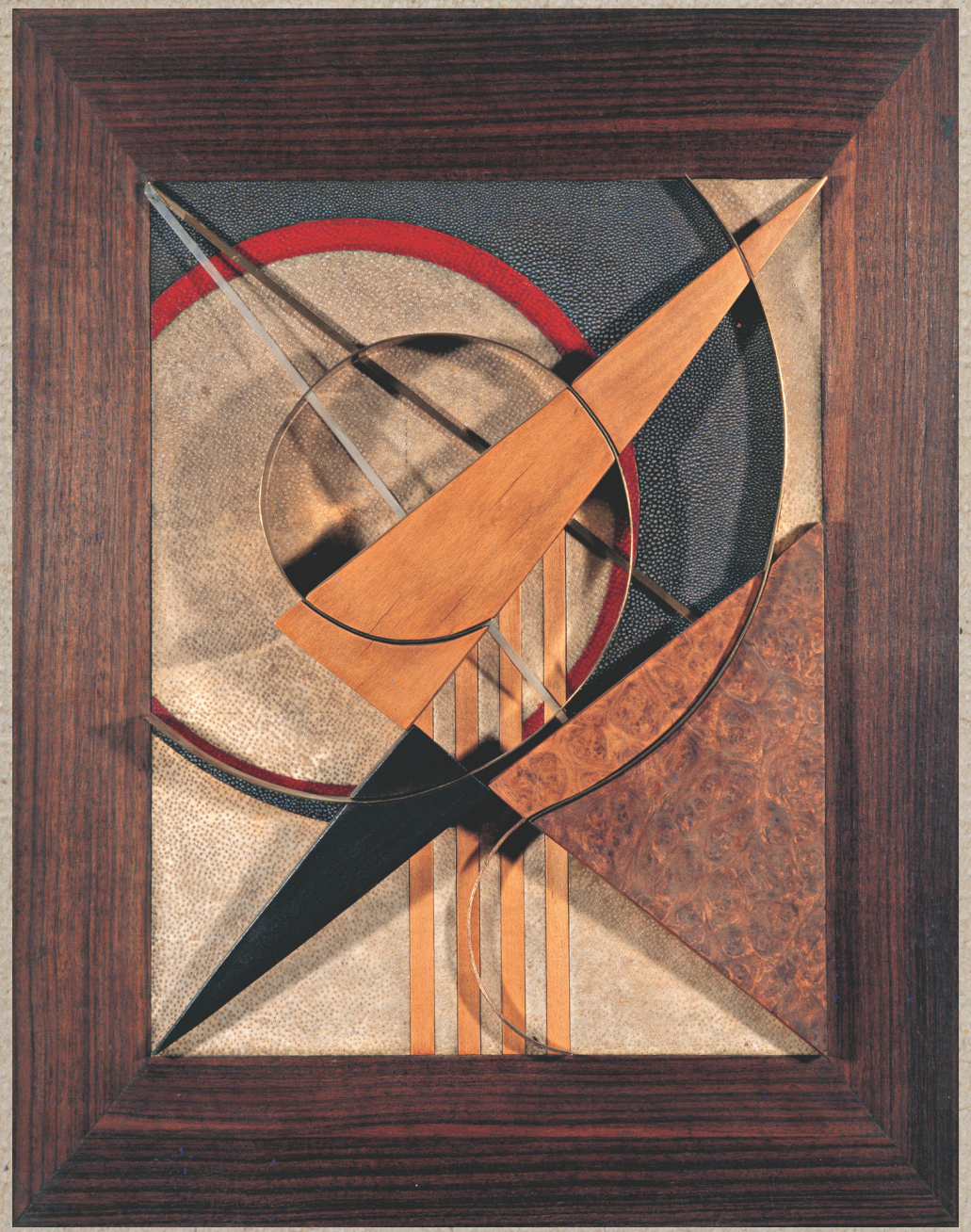

Fonte: Coleção Francisco Matarazzo Sobrinho, MAC/USP. Fotografia de Rômulo Fialdini (2011) C César Domela / AUTVIS, Brasil, 2016. 
Imagem 10-Léon Dégand mostrando um relevo de César Domela a Lourival Gomes Machado. Atrás deles, vê-se Formas expressivas, de Jean Arp, na exposição "Do figurativismo ao abstracionismo" (1949).

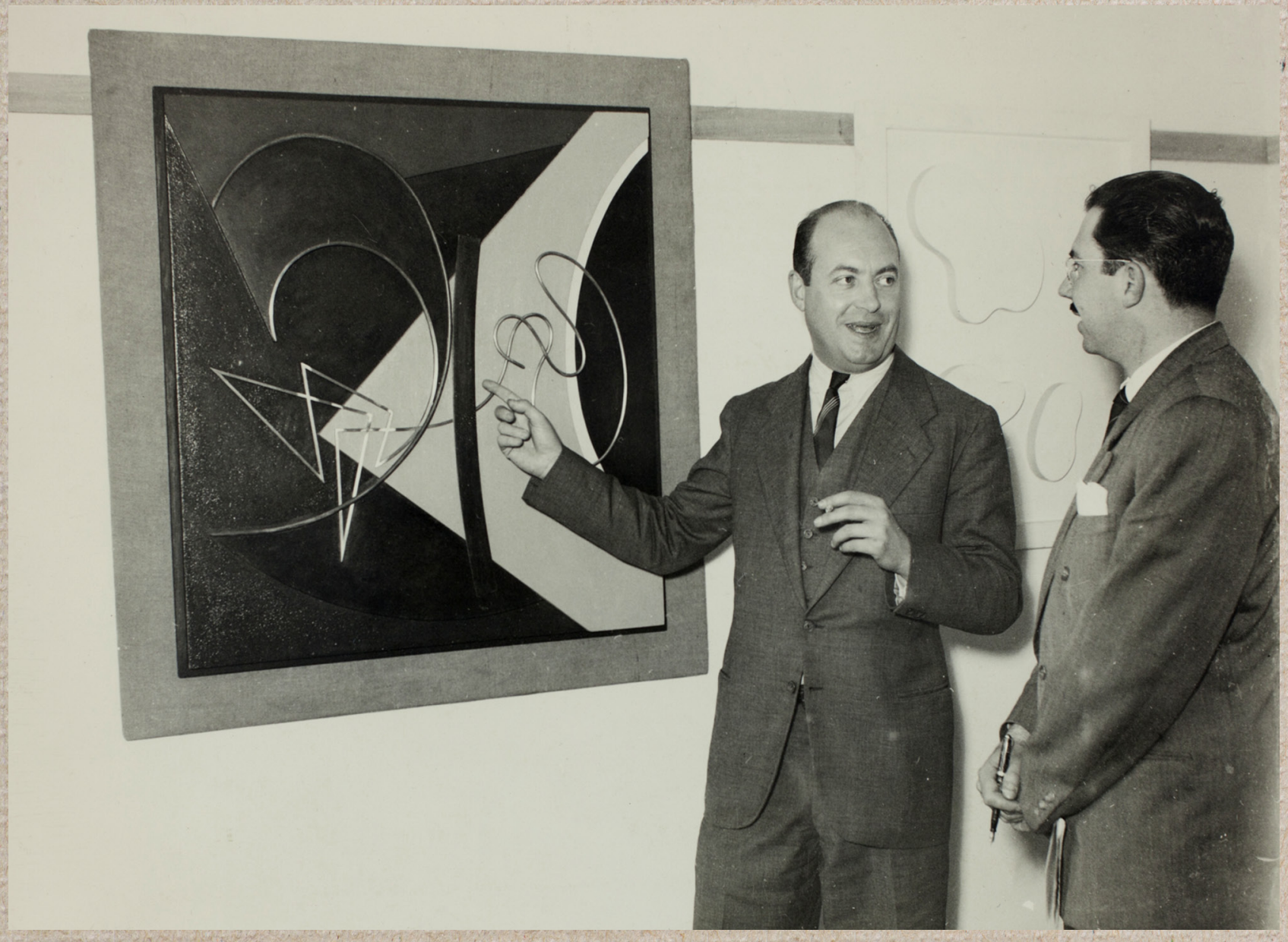

Fonte: C) Jornal das Artes (1949).

A historiografia brasileira, entretanto, dá menos ênfase à participação de artistas da chamada Segunda Escola de Paris, sobretudo aqueles que apareciam nos escritos do crítico francês Charles Estienne ${ }^{22}$. Esse é o caso de

22 A chamada Seconde École de Paris era caracterizada por um conjunto de pintores, figurativos e abstratos, que durante a II Guerra Mundial se opuseram à ocupação nazista na França e procuraram defender a arte moderna. Em 1943, criam um Salão de Maio para a promoção de suas obras. A retomada das práticas vanguardistas, assim como entendida por esses artistas, se deu por uma aproximação das experiências impressionista, pós-impressionista e do orfismo. Portanto, esses artistas eram tidos como "coloristas", uma vez que suas composições se constituíam a partir de superfícies de cor.
Jean Bazaine, descrito por Estienne como um "colorista não figurativo", isto é, não simplesmente um pintor abstrato, mas alguém cuja linguagem da pintura fundamentava-se na expressão de valores humanistas. A obra de Bazaine adquirida por Matarazzo através de Magnelli' (Imagem 11) esteve presente na mostra, bem como obras de artistas ligados aos mesmos princípios, tais como Jean Le Moal, Albert Manessier e Cérard Singier. 
Imagem 11 - Árvores à beira-d'água (1944), de Jean Bazaine. [óleo/cartolina, 65,2 × 46,2 cm]

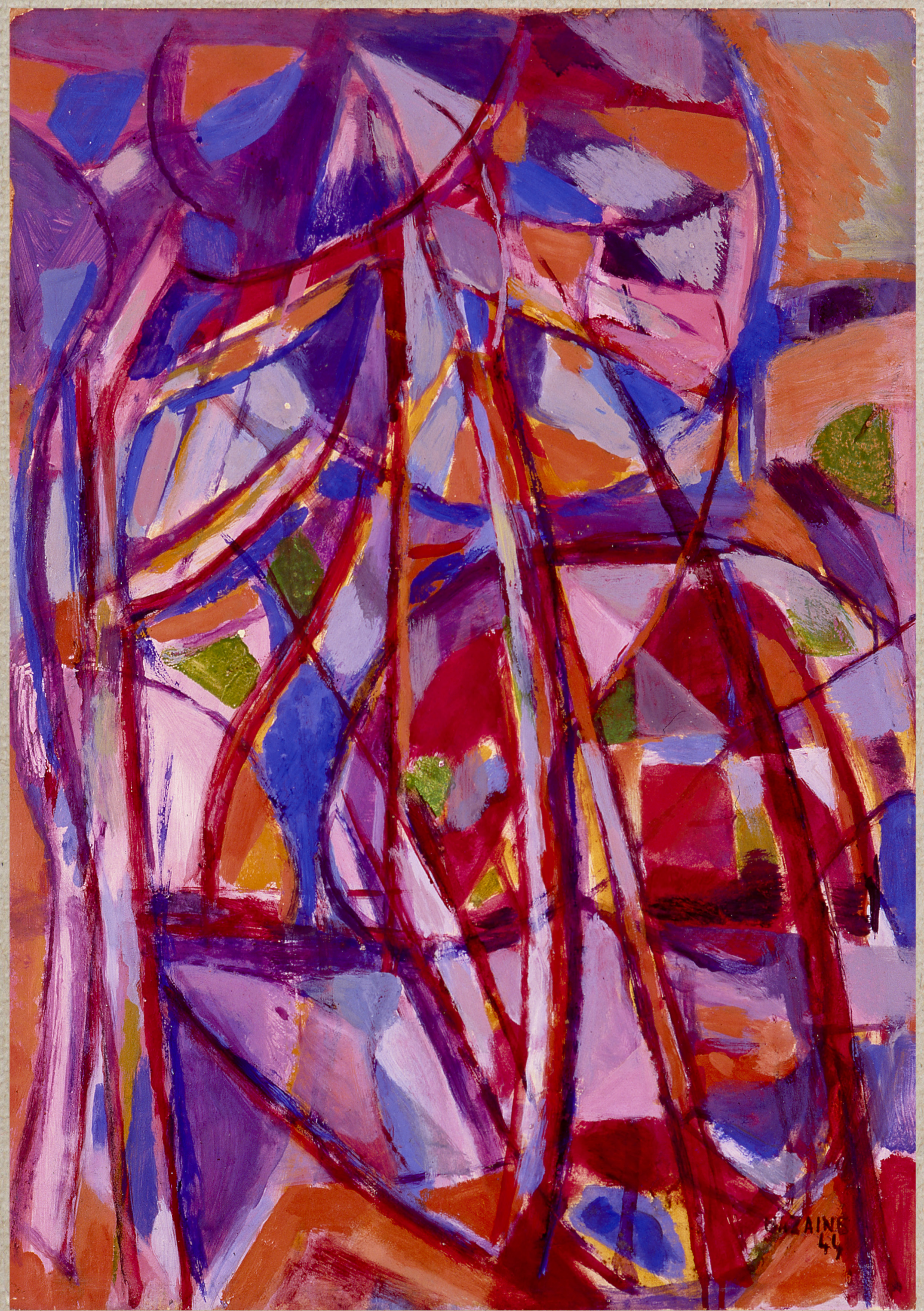

Fonte: Coleção Francisco Matarazzo Sobrinho, MAC/USP. Fotografia de Rômulo Fialdini. @ Jean Bazaine/ AUTVIS, Brásil, 2016 
A ideia de uma pintura "não figurativa" que exprimisse "valores humanistas" também podia ser encontrada no discurso de artistas como o italiano Renato Birolli (1960) naqueles mesmos anos, e depois de uma estadia sua em território francês. Ele foi um dos artistas da delegação italiana para a I Bienal de São Paulo, em 1951, ao lado de outros de seus colegas anteriormente ligados ao chamado Fronte Nuovo delle Arti, a exemplo de Afro Basaldella (ARTISTAS ITALIANOS, 1951).

Esses artistas reapareceriam na Bienal de Veneza de 1952 como parte integrante de um grupo de pintores, reformulado e lançado naquela edição da mostra, que seriam definidos como os novos pintores abstratos de seu país (XXVI Biennale di Venezia, 1952). O chamado Gruppo degli Otto nasceu a partir dos escritos do historiador e crítico de arte Lionello Venturi, que havia apenas retornado à sua terra natal, depois de um longo exílio nos Estados Unidos por suas posições antifascistas ${ }^{23}$. Ao abordar a produção dos artistas antifascistas Renato Birolli, Afro Basaldella,

23 Sobre o Gruppo degli Otto, veja-se Caramel, 1994. Sobre a crítica de Lionello Venturi de defesa desses artistas, veja-se Venturi, 1952.
Mattia Moreni, Giuseppe Santomaso, Emilio Vedova, Ennio Morlotti, Giulio Turcato e Antonio Corpora, Venturi (1950) concebeu uma base teórica para o que ele definia como uma pintura "abstrato-concreta". Tal noção implicava certa ideia de realismo como intrínseca à pintura, e como fonte de valores humanistas. Esses artistas rejeitavam qualquer tipo de abordagem naturalista na pintura, que eles imediatamente associavam às experiências recentes do Novecento Italiano. Mas o termo "realismo" era empregado como um equivalente da reminiscência de uma subjetividade coletiva, através da qual valores humanistas se exprimiam. Esse era o cerne da experiência abstrata do Cruppo degli Otto, que se dissolveu apenas dois anos depois de seu lançamento na Bienal de Véneza.

O período de promoção desses pintores abstratos italianos corresponde à segunda grande campanha de aquisições que Francisco Matarazzo Sobrinho fez na Itália para o acervo do MAM de São Paulo ${ }^{24}$. Foi exatamente

24 Veja-se pesquisa de mestrado, ainda inédita e em andamento, de Marina Barzon Silva, "O Cruppo degli Otto e as aquisições de Francisco Matarazzo Sobrinho nas XXVI e XXVII Biennali di Venezia", junto ao Programa Interunidades em Estética e História da Arte, sob minha orientação. Veja-se ainda SILVA, 2016. 


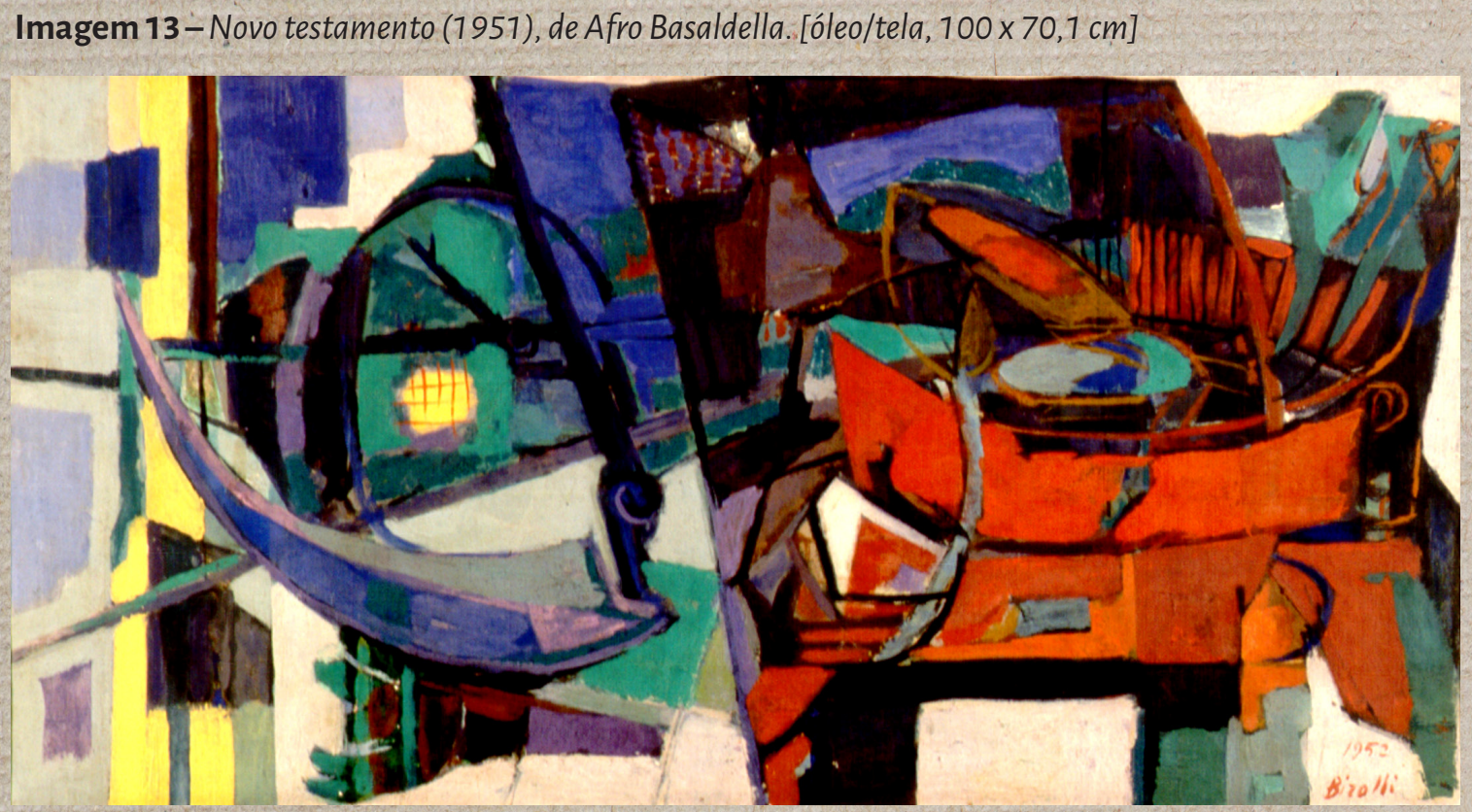

Fonte: Coleção Francisco Matarazzo Sobrinho, MAC/USP. Fotografia de Rômulo Fialdini. @) Afro Basaldella I AUTVIS, Brasil, 2016.

Imagem 14-Paisagem com fábrica (1954), de Ciulio Turcato. [óleo/tela, $159,9 \times 89,9 \mathrm{~cm}$ ]

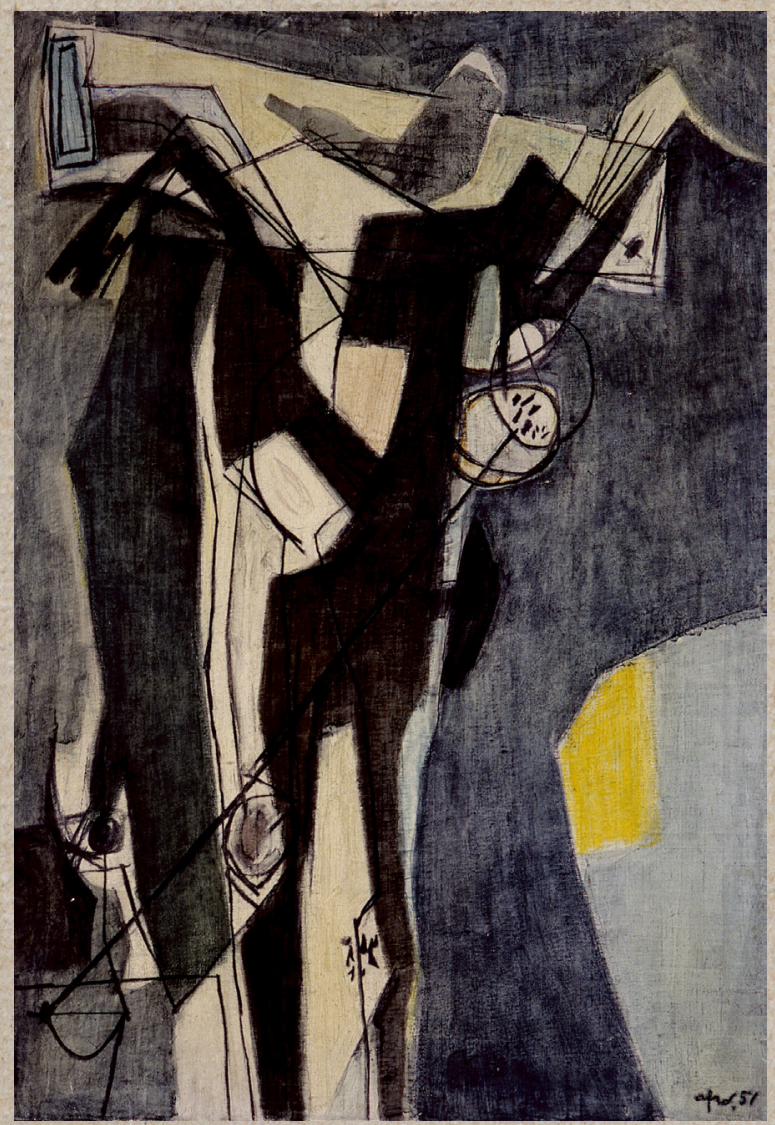

Fonte: Coleção Francisco Matarazzo Sobrinho, MACl USP. Fotografia de Rômulo Fialdini. @ GiulioTurcato / AUTVIS, Brasil, 2016. 
nas edições de 1952 e 1954 da Bienal de Veneza que ele comprou sistematicamente todos os oito pintores do grupo ${ }^{25}$. Alguns já haviam participado de uma exposição no Brasil, no antigo MAM. Em 1950, Waldemar Cordeiro, então vice-presidente do Art Club de São Paulo, organizou uma mostra do chamado Art Club di Roma (EXPOSIÇÃO DO ART CLUB DE ROMA, 1950). Nela, obras de Antonio Corpora e Giulio Turcato foram vistas. O pequeno catálogo da exposição também dava um breve relato da criação do Art Club di Roma (fundado em 1945), e que havia estabelecido o que Cordeiro, em seu texto de apresentação, chamava de "novos endereços estilísticos da península". Eles eram marcados pela ruptura com as tendências "naturalistas neoclássicas" que haviam caracterizado o período do entre guerras, dominado pelo Novecento Italiano e pela Scuola Romana. Ele falava no rompimento com a figura, que em suas palavras era "um obstáculo para o desenvolvimento da expressão plástica".

25 Como exemplos, veja-se as obras de Renato Birolli, Afro Basaldella e Giulio Turcato compradas nessas duas edições (figuras 12, 13 e 14).
A ascensão de Art Clubs em algumas capitais da Europa - os primeiros sendo os de Roma e Viena - nunca foi estudada a fundo. Alguns documentos sobre sua atividade sugerem que eles formavam uma nova associação internacional de artistas, para intercâmbio de ideias sobre as novas linguagens de expressão dentro da experiência de abstração ${ }^{26}$. Esse debate parecia fazer uso do termo "concreto" ou "arte concreta" quase como um equivalente de práticas e vertentes dentro dos grupos de artistas discutidos e adquiridos no Brasil, para compor o acervo do anti-

26 A exemplo de um recorte de jornal encontrado na documentação do artista austríaco Gustav Kurt Beck (membro-fundador e primeiro presidente do Art Club de Viena): "Die Erröffnung der Crossen Art Club Ausstellung in Turin" [A abertura da grande exposição do Art Club em Turim], datado de 25 de abril de 1953, mas sem referência do veículo (Fundo Gustav Kurt Beck, Mappe 1, Archiv/Künstlerdokumentation, Österrechische Galerie Belvedere, Viena, Áustria). Agradeço também à pesquisadora Heloísa Espada, que em seu projeto de pós-doutorado sob minha supervisão, localizou em arquivos estrangeiros algumas revistas publicadas pelo Art Club di Roma e o catálogo de uma exposição que revia a história da agremiação (SIMONGINI \& CONTI, 1999'). Ainda sobre as relações entre o concretismo paulista, em especial, a figura de Waldemar Cordeiro, com - Art Club e os grupos abstratos italianos do período, ver a comunicação, de Heloísa Espada (2016), "Waldemar Cordeiro, The Rome Art Club, and its Consequences on the Ruptura Manifesto", proferida na mesma sessão em que apresentamos a presente pesquisa, no XIII Congresso da Brazilian Studies Association (BRASA), em março de 2016. Finalmente, é possível inferir que a emergência do Art Club, tendo como o primeiro o de Roma, parecia ocupar o lugar deixado pelos sindicatos regionais e o sindicato nacional de artistas, que durante a era fascista haviam dominado o sistema das artes na Itália, através de seu programa de exposições, sua ingerência na seleção de artistas que participariam nas edições de grandes mostras nacionais (como a Quadrienal de Roma), e na delegação italiana para a Bienal de Veneza. 
go MAM de São Paulo. Ao constituir a narrativa sobre a I Bienal de São Paulo, a historiografia brasileira tendeu a dar maior ênfase à presença do concretismo, expresso na imagem do Prêmio Regulamentar Estrangeiro de Escultura, da obra "Unidade Tripartida", do artista suíço Max Bill27. Naquele momento, Bill já estava engajado no projeto da Hochschule für Gestaltung de Ulm, na Alemanha, considerada herdeira direta da Bauhaus nos anos 1950, por sua vez fundada na prática da abstração e das experiências do construtivismo.

As aquisições que discutimos revelam que estamos num contexto artístico bem mais variado e diverso do que pensamos, no qual o termo "concreto" ganha diferentes roupagens e é muito nuançado por práticas artísticas que incorporam certa noção de realismo. No caso italiano, "abstrato" e "concreto" são termos tomados como diferentes dimensões da obra de arte em sua própria essência, como proposto por Lionello Venturi (1950). Esse contexto é claramente representado no acervo. do antigo MAM, com programas siste-

27 Atualmente, como as demais obras aqui tratadas, pertencente ao acervo do MAC/USP. máticos de aquisição que envolveram diretamente os agentes desse debate. Ademais, tais agentes não eram meros "outsiders" apenas sendo importados e transplantados para o Brasil, mas pareciam ter estabelecido um diálogo importante com o meio artístico local-como no caso de Waldemar Cordeiro. Encontramos também ecos dos argumentos e das teorias de Venturi no ensaio de Mário Pedrosa para a conferência promovida por Dégand no quadro da exposição "Do figurativismo ao abstracionismo", em sua itinerância para o Rio de Janeiro, em 1949 (DÉGAND, 1949a).

Além disso, essas aquisições refletem um período de intensas confrontações de experiências muito distintas de abstração, que talvez tenham em comum sua recónexão com práticas vanguardistas das duas primeiras décadas do século $X X$, interpretadas à luz de dois aspectos. O primeiro deles é, de fato, a polarização do debate político do imediato pós-guerra, no qual a forte posição tomada pelos intelectuais do Partido Comunista questionava a abstração geométrica pura como uma prática eminentemente burguesa. O segundo aspecto diz respeito à necessidade desse meio se re- 
conectar com o debate internacional, ao tentar reposicionar a Itália como lugar da vanguarda artística.

Nesse período, observa-se, portanto, um intercâmbio entre os termos "abstração geométrica", "arte concreta", "vanguarda" e "construtivismo", todos entendidos como expressão da experiência mais nova e mais radical da linguagem da arte moderna, ao mesmo tempo oposta às correntes de uma ideia de um "modernismo clássico" - muito maculado pela sua ligação com a propaganda cultural totalitária entre a Itália, a União Soviética e a Alemanha. O que a arte concreta viria a ser ao longo da década de 1950 deve ser considerada como resultante do desenvolvimento de uma dessas diferentes tendências, enquanto outras parecem ter se desdobrado em práticas abstratas informais - caso justamente dos artistas italianos colecionados no antigo MAM de São Paulo28.

Ao compararmos os dois programas de aquisição realizados porFrancisco Matarazzo Sobrinho (o primeiro entre 19461947, e o segundo entre 1952-1954),

28 Nesse sentido, veja-se a análise de Jachec (2007) em que esses artistas teriam sido cooptados pela noção de "informalismo", que por sua vez, seria representativo de uma "identidade europeia" nos anos 1950. há uma clara ruptura na concepção de arte moderna que estava em debate no período. Embora a primeira aquisição já contemplasse artistas que emergiriam como os novos pintores abstratos da Itália no início da década de 1950, a escolha das obras foi feita pouco antes dessa virada, quando alguns artistas do Gruppo degli Otto estiveram associados ao grupo milanês Corrente di Vita Ciovanile, e se engajaram num ativismo antifascista. De todo modo, estamos falando ainda de práticas figurativas, inspiradas no expressionismo e no fauvismo. Já a segunda campanha de aquisição abraça deliberadamente as novíssimas tendências abstratas na Itália, que naquele território se opunham frontalmente às linguagens classicizantes da era fascista.

Finalmente, encerramos afirmando que o papel que o MoMA de Nova York e seus agentes tiveram ainda está por ser plenamente estudado, principalmente a figura de Nelson Rockefeller ${ }^{29}$. Seja do ponto de vista das aquisições feitas, ou da estruturação do MAM e da Bienal de São Paulo, as ligações do Brasil parecem ser muito mais

29 A esse respeito, ver Tota (2014), em especial o capítulo 7 ("Arte e cultura: receitas para a elite brasileira"). O autor ainda se vale da historiografia e bibliografia brasileira corrente e incorre em alguns equívocos em relação à criação do antigo MAM e a formação de seu acervo. 
próximas da França e da Itália, do que dos Estados Unidos ${ }^{30}$. Isso não diminui o papel das iniciativas de Rockefeller na criação dessas instituições, mas elas não corresponderam - nem mesmo depois - à promoção de uma nova arte norte-americana, ou à ideia de abstração como uma linguagem artística autônoma e universal, que expressasse a imagem de uma sociedade liberal burguesa. A partir do acervo em, questão, acessamos fragmentos dessa dinâmica, ainda por ser conformada e colocada como ferramenta operacional de soft power em território latino-americano nas décadas seguintes.

30 Como demonstram pesquisas já estabelecidas de longa data, a Bienal de São Paulo tomou a sua "irmã" mais velha italiana como modelo, a tal ponto dos regulamentos de premiação serem idênticos. A este respeito, ver texto de Renata Dias Ferraretto Moura Rocco (2016a) sobre o artista Danilo di Prete e suas relações com a Bienal de São Paulo, vinculado à pesquisa de doutorado em andamento sob minha orientação intitulada "Danilo di Prețe no Brasil: entre Limões, Bienal de São Paulo e Ciccillo Matarazzo". Ver, ainda, Rocco (2016b). 


\section{Referências}

ABADIE, Daniel. Alberto Magnelli. Paris: Centre National Ceorges Pompidou, 1993.

ARTISTAS ITALIANOS de hoje na la. Bienal do Museu de Arte Moderna de São Paulo [texto de apresentação de Rodolfo Pallucchini]. Veneza: Officine Grafiche Carlo Ferrari, 1957.

ALMEIDA, Fernando Azevedo de. O franciscano Ciccillo. São Paulo: Pioneira, 1976.

AMARAL, Aracy. Arte para quê? A preocupação social na arte brasileira 1930-1970. São Paulo: Studio Nobel, 2003.

BELLI, Gabriella (Org.). Afro: il periodo americano. Milão: Mondadori/Electa Mart, 2012.

BARROS, Regina Teixeira de Revisão de uma história: a criação do Museu de Arte Moderna de São Paulo, 1946-1949. 2002. Dissertação (Mestrado em História e Crítica da Arte)-Escola de Comunicação e Artes, Universidade de São Paulo. 2002.

BIROLLI, Renato. Taccuini 7936-7959. Milão: Einaudi, 1960.

BIROLLI, Zeno; RUSCONI, Paolo (Org.). Renato Birolli: Necropoli e Paesaggio Adriatico. Milão: Scalpendi, 2010.

BOSSAGLIA, Rossana. (1976). II Novecento Italiano. Milão: Charta, 1995.

CANNISTRARO, Phillip; SULLIVAN, Brian. II Duce's Other Woman. Nova York: William Morrow \& Co., 1993.

CARAMEL, Luciano. Arte in Italia, 1945 - 1960. Milano: Vita e Pensiero, 1994.

DÉGAND, Léon (Org.). Do figurativismo ao abstracionismo. São Paulo: Museu de Arte de São Paulo, 1949a.

Onovo edifício da Sul América Terrestres, Marítimose Acidentes-Sucursal do Rio de Janeiro, Rio de Janeiro, $1949 b$.

ESPADA, Heloísa. Waldemar Cordeiro, The Rome Art Club, and its consequences on the Ruptura Manifesto. In: BRASA - CONCRESSO INTERNACIONAL DA BRASILIAN STUDIES ASSOCIATION, 13, 2016, Providence, Rhode Island, EUA. Programa Brasa XIII. Rhode Island: Brown University, 2016. Disponível em: <http://www.brasa.org/wordpress/wp-content/uploads/2015/10/UECS_BRASA-1. pdf>. Acesso em: mar. 2017: 
EXPOSIÇÃO DO ART CLUB DE ROMA [texto de apresentação de Waldemar Cordeiro]. São Paulo: Museu de Arte Moderna de São Paulo, 1950.

FABRIS, Annateresa (Org.). História e (m) movimento. Atas do Seminário MAM 60 anos. São Paulo: Museu de Arte Moderna de São Paulo, 2008.

JACHEC, Nancy. Politics and Painting at the Venice Biennale, 1948-64. Italy and the Idea of Europe. Manchester: Manchester University, 2007.

LIFFRAN, Françoise. Légerie du Duce. Paris: Seuil, 2009

LOURENÇO, Maria Cecília França. Museus acolhem o moderno. São Paulo: Edusp, 1999.

MACALHÃES, Ana Conçalves. O debate crítica na exposição do Edifício Sul América, Rio de Janeiro, 1949. In: CONDURU, Roberto Conduru; SIQUEIRA, Vera Beatriz Siqueira (Orgs.). Anais do XXIX Colóquio do Comitê Brasileiro de História da Arte. Historiografia da arte no Brasil: um balanço das contribuições recentes. Rio de Janeiro: Comitê Brasileiro de História da Arte, 2009, p. 120-128. Disponível em: <http://www.cbha.art.br/coloquios/2009/anais/pdfs/anais_coloquio_2009.pdfs. Acesso em: mar. 2017

Achille Funi nella Collezzione del MAC USP. Rivista L'Uomo Nero: Materiali per una storia delli arti della Modernità, Milão, CUEM, p. 349-358, 2011.

Classicismo moderno. Margherita Sarfatti e a pintura italiana no acervo do MAC USP. São Paulo: Alameda, $2016 a$.

The Quest for Abstract Art in Brazil: Revisiting the Primary Collection of the São Paulo Museum of Modern Art, 1946-1952. In: BRASA - CONGRESSO INTERNACIONALDA BRASILIAN STUDIES ASSOCIATION, 13, 2016, Providence, Rhode Island, EUA. Programa Brasa XIII. Rhode Island: Brown University, 2016b. Disponível em: <http://www.brasa.org/wordpress/wp-content/ uploads/2015/10/UECS_BRASA-1.pdf>. Acesso em: mar. 2017.

MILLIET, Sérgio. Pintura quasesempre. Porto Alegre: OClobo, 1944.

NASCIMENTO, Ana Paula. MAM: Museu para a metrópole. 2003. Tese (Doutorado em História da Arte e Arquitetura) - Faculdade de Arquitetura e Urbanismo, Universidade de São Paulo. 2003. Disponível em: <http://www.teses.usp.br/teses/disponiveis/16/16131/tde-12012005-122318/pt-br. php>. Acesso em: mar. 2017.

OSÓRIO, Luiz Camillo; FABRIS, Annateresa (Orgs.). MAM 60 anos, São Paulo: Museu de Arte Moderna de São Paulo, 2008.

ROCCO, Renata Dias Ferraretto Moura. Danilo di Prete no Brasil: sobre relatos de vida, a criação da Bienal de São Paulo e o arquivo da família. In: FREIRE, M.C.M. (Org.). Escrita da História e (re) construção das memórias: arte e arquivo's em debate., São Paulo: MAC USP/Annablume, 201.6a. p. 335340. 
Considerações sobre a I Bienal de São Paulo: uma correspondência de Marco Valsecchi a Rodolfo Pallucchini. Revista de História da Arte e Arqueologia, Campinas, n. 25, 2016b [no prelo].

SILVA, Marina Barzon. O Astratto e Concreto de Lionello Venturi e o Gruppo degli Otto. Revista de , História da Arte e Arqueologia, Campinas; n. 25, 2016 [no prelo].

SIMONGINI, Gabrielle; CONTI, Gisella. Cat. exp. Art Club 7.945-7964. Parma: Galleria d'Arte Niccoli, 24 de outubro de 1998 a 20 de janeiro de 1999.

TOLEDO, Carolina Rossetti de. As doações Nelson Rockefeller no acervo do Museu de Arte Contemporânea da Universidade de São Paulo. 2015. Dissertação (Mestrado em Estética e História da Arte), Museu de Arte Contemporânea, Universidade de São Paulo. 2015. Disponível em: <http:/I www.teses.usp.br/teses/disponiveis/93/93131/tde-29012016-105805/pt-br.php>. Acesso em: 10 jan. 2017.

TOTA, Antonio Pedro O amigo americano. Nelson Rockefeller e o Brasil São Paulo: Companhia das Letras, 2014.

VENTURI, Lionello. Astratto e Concreto. Rivista Trimestrale di Arte Cinema Teatro Musica Moda della Biennale di Venezia, n. T, 1950.

Otto pittori italiani. Roma: De Luca, 1952.

XXVI BIENNALE DI VENEZIA. Veneza: Alfieri, 1952. 


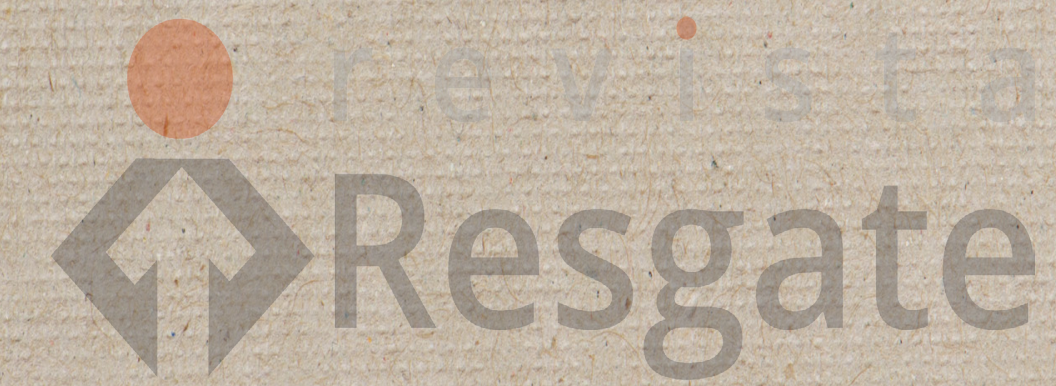

